\title{
An Improved Model for FE Modeling and Simulation of Closed Cell Al-Alloy Foams
}

\author{
MD. Anwarul Hasan \\ Department of Mechanical Engineering, University of Alberta, Edmonton, AB, Canada T6G2G8 \\ Correspondence should be addressed to MD. Anwarul Hasan, mhasan@ualberta.ca
}

Received 22 February 2010; Revised 3 June 2010; Accepted 11 July 2010

Academic Editor: J. W. Gillespie

Copyright (C) 2010 MD. Anwarul Hasan. This is an open access article distributed under the Creative Commons Attribution License, which permits unrestricted use, distribution, and reproduction in any medium, provided the original work is properly cited.

Cell wall material properties of Al-alloy foams have been derived by a combination of nanoindentation experiment and numerical simulation. Using the derived material properties in FE (finite element) modeling of foams, the existing constitutive models of closed-cell Al-alloy foams have been evaluated against experimental results. An improved representative model has been proposed for FE analysis of closed-cell Al-alloy foams. The improved model consists of a combination of spherical and cruciform-shaped cells similar to those of Meguid et al.'s cruciform-hemisphere model (Finite Elem. Anal. Design: 2002, 38, 631). However, the spherical cells, which are smaller in size, are made of thicker cell walls in the new improved model compared to the cruciform-shaped cells, based on observation of the underlying Al-alloy foams. The compressive mechanical properties of Al-3wt. $\% \mathrm{Si}-2 \mathrm{wt} . \% \mathrm{Cu}-2 \mathrm{wt} . \% \mathrm{Mg}$ alloy foams of relative density $12 \%-20 \%$ have been obtained by simulation using the improved representative model. While the traditional foam models overpredict the foam strength, the new weaker-cruciform-stronger-hemisphere model is found to predict the foam properties with much better accuracy. It is found that the proposed new model is capable of producing all three different types of deformation pattern of closed-cell metal foams, namely, uniform deformation, layerwise deformation, and the progressive deformation from the locations of lowest densities and highest impurities to those of higher densities and lower impurities.

\section{Introduction}

Light weight metallic foams can be used in the construction of composite panels, foam-filled shells and tubes, and many other lightweight composite structures [1] with high structural efficiency. A huge volume of literature already exists on the production [2-4], characterization [5-12], numerical simulation [13], and industrial application [1417] of Al-alloy foams.

This study particularly deals with the modeling and simulation of closed-cell Al-alloy foams for numerical study of its mechanical properties and deformation behaviors. As pointed out by Santosa and Wierzbicki [18], the major difficulty in predicting the crushing strength of closedcell aluminum foams through numerical simulation lies in obtaining their cell wall material properties. In recent research publications, for example, see [5], it has been shown that the material properties of Al-foam cell wall can be identified by performing nanoindentation test on the cell wall and simulating the test results using numerical FE codes. Thus, the difficulties in obtaining material properties of foams have already been solved to some extent. As the successful widespread application of finite element codes for analysis of structures and components rests upon both the accuracy of the material properties and the numerical model, it is therefore the next step that the existing numerical models that have been proposed so far by various researchers for simulation of Al-foams be verified against experimental results using real cell wall material properties in the simulation.

In this paper, a numerical study of closed-cell Al-alloy foams has been performed using the cell wall material properties obtained by a combination of nanoindentation test and FE simulation with various existing numerical models of foams. Results showed that the FE simulations using conventional foam models over predict elastic modulus and crushing strength of foams when the real cell wall material properties are applied to the models. An improved model, named weaker-cruciform-stronger-hemisphere model, has 
been developed which is shown to be able to predict behaviors of closed-cell Al-alloy foams in much better agreement with the experimental results.

\section{Experiment}

2.1. Materials and Specimens. Closed-cell Al-alloy foams of composition $\mathrm{Al}-3 \mathrm{wt} \% \mathrm{Si}-2 \mathrm{wt} \% \mathrm{Cu}-2 \mathrm{wt} \% \mathrm{Mg}$ and relative densities of $12 \%$ to $20 \%$ were studied in this work. The foams were produced using the powder metallurgical method [2]. In this method, powders of $\mathrm{Al}-\mathrm{Si}-\mathrm{Cu}-\mathrm{Mg}$ alloy and $\mathrm{TiH}_{2}$ are mixed in appropriate proportion (99:1 in our study), which is then cold compacted (at a pressure of $4 \mathrm{MPa}$ ), hot extruded (to a ratio $20: 1$ and at a temperature $430^{\circ} \mathrm{C}$ ) and finally foamed in a preheated furnace (at a temperature $700^{\circ} \mathrm{C}$ for 15 minutes).

Skin was removed from the produced foams and specimens of $10 \mathrm{~mm}$ thickness were taken from each of the foam samples, which were mounted into thermo-set epoxy resin for nanoindentation test. For compression test, specimens were taken with a dimension $35 \times 35 \times 40 \mathrm{~mm}$ so that each side of a specimen has a length greater or equal to seven times the average cell diameter [1].

2.2. Cell Wall Material Properties. For obtaining the material properties of the foam cell walls, nanoindentation test was performed on the foam cell walls using a nanoindenter XP with a Berkovich tip indenter. The Young modulus of the foams was evaluated from the unloading loadnanoindentation curve using Oliver and Pharr's method while the yield stress and the stress-strain curve of the cell wall material were evaluated using FE simulation. Detail description of the procedure can be found in Amkee Kim et al. [5]. Here, the procedure is outlined briefly.

The FE simulation of nanoindentation load-displacement curve was performed by FE code ABAQUS using a two-dimensional axisymmetric model with a semiangle $\alpha=70.3^{\circ}$. The model consisted of a total 10718 node and 9878 (CAX4) elements. The contact utilized between indenter and the specimen was sliding through contact. Material properties used for the indenter were Young's modulus, $E=1103 \mathrm{GPa}$ and Poison's ratio, $v=0.07$. For the specimen, an elastoplastic material with Young's modulus and Poison's ratio values as derived from the nanoindentation test was adopted. To obtain the stressstrain curve of the cell wall material, it was assumed that the yield point $\left(\sigma_{y}, \varepsilon_{y}\right)$ of the curve satisfies the power law equation $\sigma=k \varepsilon^{n}$ such that $\sigma_{y}=k \varepsilon_{y}^{n}$. For simplification, the yield strain was taken to be 0.00432 (same as that of 322 precursor material) in all cases. Initially, the strain hardening exponent, n, was kept fixed at a value obtained from literature for similar alloys. Thus, the unknown parameters remained in the power law equation were $\sigma_{y}$ and $k$.

The value of yield stress $\sigma_{y}$ was then assumed and corresponding value of $k$ was computed from the relation, $\sigma_{y}=k \varepsilon_{y}^{n}$. Substituting the value of $k$ and $n$ in the power law equation, $\sigma=k \varepsilon^{n}$ and varying the value of $\varepsilon$, a piecewise-linear stress-strain curve with 4 points, as shown

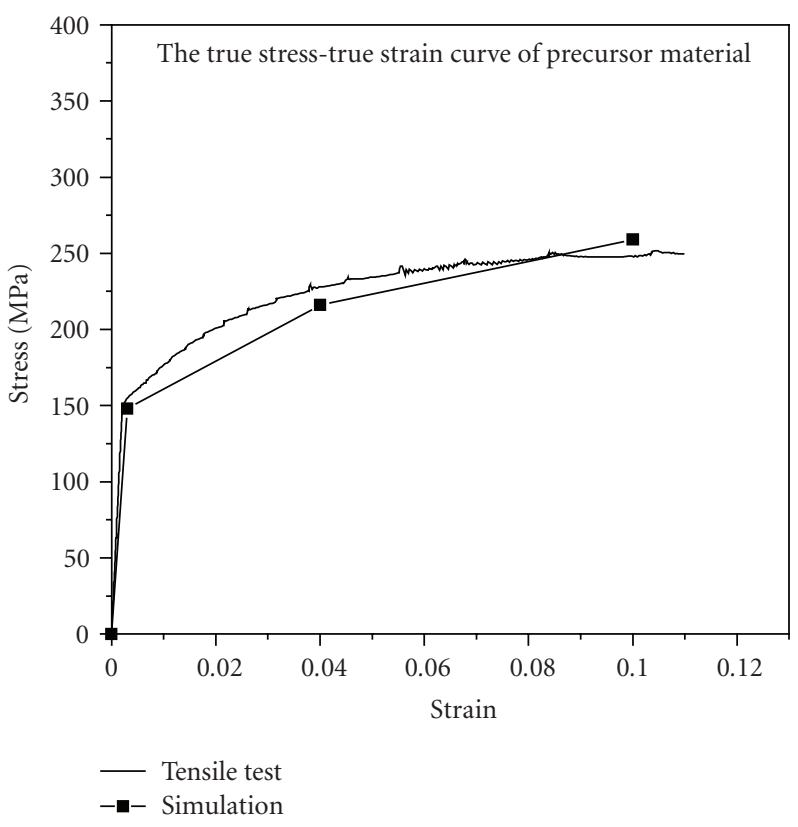

FIGURE 1: Comparison of stress-strain curves from simulation and tensile test (322 precursor).

in Figure 1, was constructed. The simulation was then run and the numerically obtained load-displacement curve was compared with the experimental one. Based on the difference between the two curves, a different value of yield stress was chosen and the procedure was repeated several times. Finally, when the curve from numerical simulation became close to the experimental curve, a few more times the simulation was run adjusting both the yield stress and $n$-value to obtain the best fit curve. When the simulated curve showed a good agreement with the experimental curve, the proposed set of material properties used in that iteration was accepted as the property of that specimen. The procedure described above for obtaining the stress-strain curve was at first applied to the precursor material and the obtained curve was compared with the curve obtained from the conventional uniaxial tensile test on the precursor material. Figure 1 shows that the curve obtained from simulation is in reasonably good agreement with the conventional tensile test result. The same method was then utilized for obtaining the stress-strain curves of the foam cell wall and the obtained curve is shown in Figure 2.

\subsection{Measurement of Compressive Mechanical Properties of} Foam. Compressive mechanical properties of the foams were measured by performing quasistatic uniaxial compression test on the specimens using a computer controlled servohydraulic MTS $810 \mathrm{~m} / \mathrm{c}$. The tests were performed under displacement control mode at a constant displacement rate of $0.02 \mathrm{~mm} / \mathrm{s}$. Nominal stress and strain were computed from the load cell and cross head displacement data recorded by the data acquisition system. 


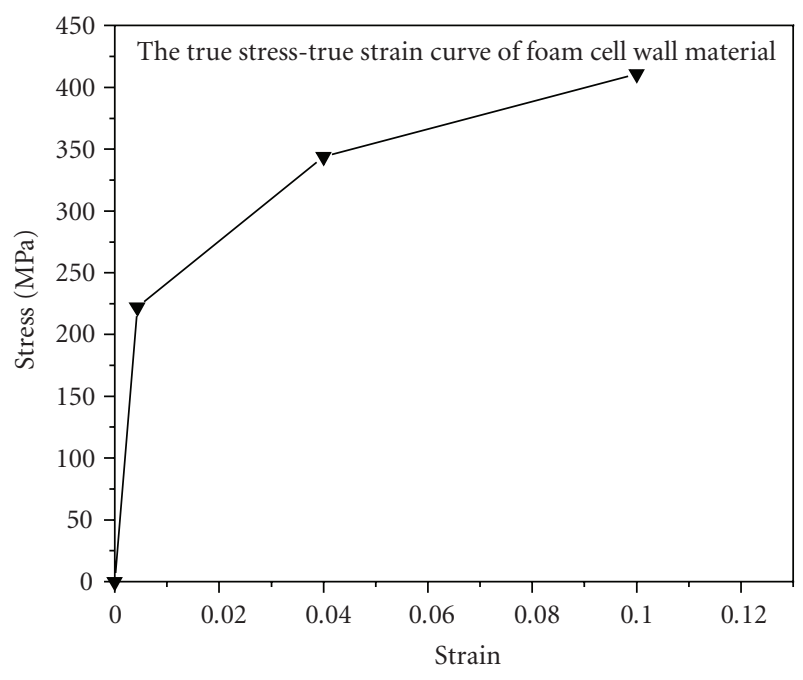

Figure 2: The stress-strain curve of 322 and Foam Tech foams obtained from simulation.

\section{FE Modeling and Simulation}

Great strides have been made so far in representing closedcell Al-alloy foams. As a result, a number of models have been developed and many of them have been implemented in the commercial FE codes. An overview of nine constitutive models claiming to be applicable for structural considerations of Al-foams, four of which can be found in LSDYNA, one in ABAQUS and others in the papers of Schreyer et al., Ehlers et al., Deshpande et al., and Miller et al., respectively, has been described in [19]. All of these models represent the Al-alloy foams as solid materials with certain prescribed constitutive laws which are based on some empirical equations formulated from experimental results. Other than these empirical/semiempirical models, several representative models have also been proposed by researchers, some of which are summarized below.

3.1. Gibson and Ashby's Skeleton Cubic Cell Model. Gibson et al. proposed a skeleton cubic cell model [20] to represent the closed-cell foams. Performing a dimensional analysis on the model they established a set of equations for the elastic modulus, plastic plateau stress and densification strain of the foams given by

$$
\begin{aligned}
\frac{E^{*}}{E_{s}} & =C_{1} \phi^{2}\left(\frac{\rho^{*}}{\rho_{s}}\right)^{2}+C_{1}(1-\phi)\left(\frac{\rho^{*}}{\rho_{s}}\right), \\
\frac{\sigma_{p l^{*}}}{\sigma_{y s}} & =C_{2} \phi^{3 / 2}\left(\frac{\rho^{*}}{\rho_{s}}\right)^{3 / 2}+C_{2}(1-\phi)\left(\frac{\rho^{*}}{\rho_{s}}\right), \\
\varepsilon_{d} & =C_{3}\left[1-1.4\left(\frac{\rho^{*}}{\rho_{s}}\right)+0.4\left(\frac{\rho^{*}}{\rho_{s}}\right)^{3}\right],
\end{aligned}
$$

where $E^{*}, \sigma_{p l}^{*}$ and $\rho^{*}$ are Young's modulus, plateau stress and density of foam while $E_{s}, \sigma_{y s}$, and $\rho$ are the same properties for solid cell wall material. $C_{1}, C_{2}, C_{3}$, and so forth are empirical constants, and $\phi$ is the volume fraction of solid contained in cell edges. The values of $\phi, C_{1}, C_{2}$, and $C_{3}$ are obtained by best fitting the experimental data which vary from foams to foams. For closed-cell Al-alloy foams, like the ones used in this study the above set of equations, after solving, took the form [21]

$$
\begin{aligned}
\frac{E^{*}}{E_{s}} & =(0.1-1.0)\left[0.5\left(\frac{\rho^{*}}{\rho_{s}}\right)^{2}+0.3\left(\frac{\rho^{*}}{\rho_{s}}\right)\right], \\
\frac{\sigma_{p l}^{*}}{\sigma_{y s}} & =(0.1-1.0)\left[0.5\left(\frac{\rho^{*}}{\rho_{s}}\right)^{3 / 2}+0.3\left(\frac{\rho^{*}}{\rho_{s}}\right)\right], \\
\varepsilon_{d} & =(0.9-0.1)\left[1-1.4\left(\frac{\rho^{*}}{\rho_{s}}\right)+0.4\left(\frac{\rho^{*}}{\rho_{s}}\right)^{3}\right] .
\end{aligned}
$$

3.2. Simone and Gibson's Tetrakaidecahedral Model. Simone and Gibson used a unit tetrakaidecahedral cell model [22], and performing the FE analysis using shell elements, they found

$$
\begin{aligned}
\frac{E^{*}}{E_{s}} & =0.32\left(\frac{\rho^{*}}{\rho_{s}}\right)^{2}+0.32\left(\frac{\rho^{*}}{\rho_{s}}\right), \\
\frac{\sigma_{p l}^{*}}{\sigma_{y s}} & =0.33\left(\frac{\rho^{*}}{\rho_{s}}\right)^{3 / 2}+0.44\left(\frac{\rho^{*}}{\rho_{s}}\right),
\end{aligned}
$$

where the parameters have the same meanings as in (1) to (6).

3.3. Santosa and Weirzbicki's Truncated Cube Model. Assuming the foams to be consisted of a densely packed lattice of small and large cells, Santosa and Weirzbicki introduced a multiple cell model known as the truncated cube model [18]. Figure 3 shows the cell morphology and a foam building block of truncated cube model. The model consisted of regular and symmetric unit cells assembled using truncated cube sections. Adapting the concept of the super folding element, they derived the analytical solution for the crushing strength of their model as [18]

$$
\frac{\sigma_{p l}^{*}}{\sigma_{0}}=0.63\left(\frac{\rho^{*}}{\rho_{s}}\right)^{3 / 2}+0.07\left(\frac{\rho^{*}}{\rho_{s}}\right)+0.8\left(\frac{\rho^{*}}{\rho_{s}}\right)^{2},
$$

where

$$
\sigma_{0}=\left(\frac{\sigma_{y} \sigma_{u}}{1+n}\right)^{1 / 2}=\left(\frac{\sigma_{y} 2 \sigma_{y}}{1+n}\right)^{1 / 2},
$$

$\sigma_{o}$ is known as plastic flow stress, while $\sigma_{y}, \sigma_{u}$ and $n$ are the yield stress, the ultimate stress and the strain hardening exponent of the cell wall material. For numerical simulation, the relative density of foam for this model is given by

$$
\frac{\rho_{\text {foam }}}{\rho_{\text {solid }}}=3\left(\frac{t}{W}\right)+(4 \sqrt{3}-6)\left(\frac{t}{W}\right)\left(\frac{c}{W}\right)^{2},
$$

where, $t, c$, and $W$ are the cell wall thickness, half of the diagonal of the pyramidal section and width of a unit cell, respectively. 


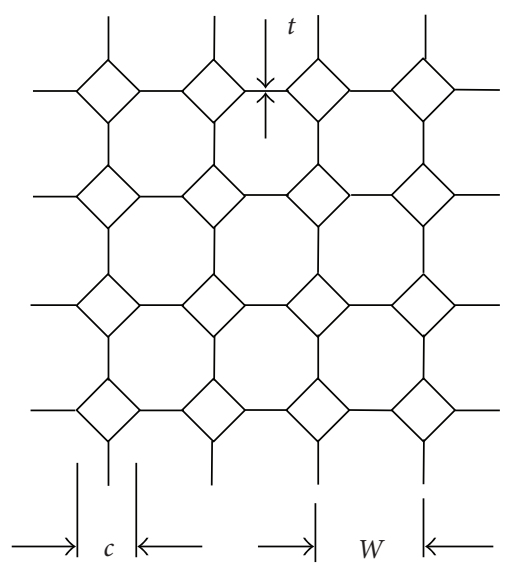

(a)

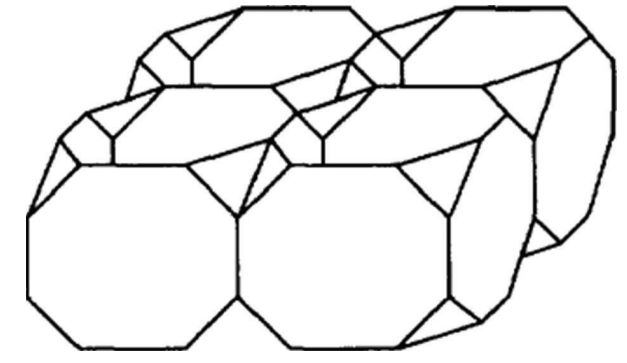

(b)

FIGURE 3: Schematic diagram of the truncated cube model (a) top view (cell morphology), and (b) isometric view (3-D structure) of the model.

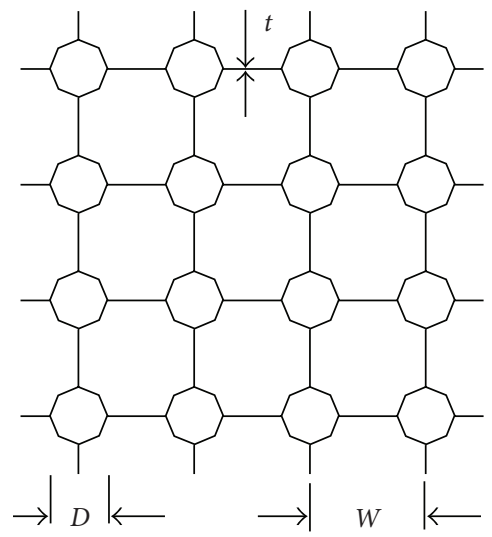

(a)

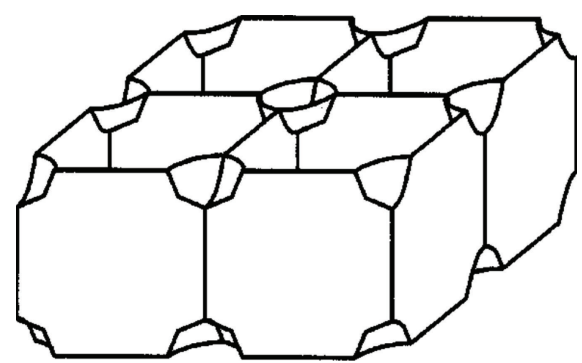

(b)

FIGURE 4: Schematic diagram of the cruciform-hemisphere model (a) top view (cell morphology), and (b) isometric view (3-D structure) of the model.

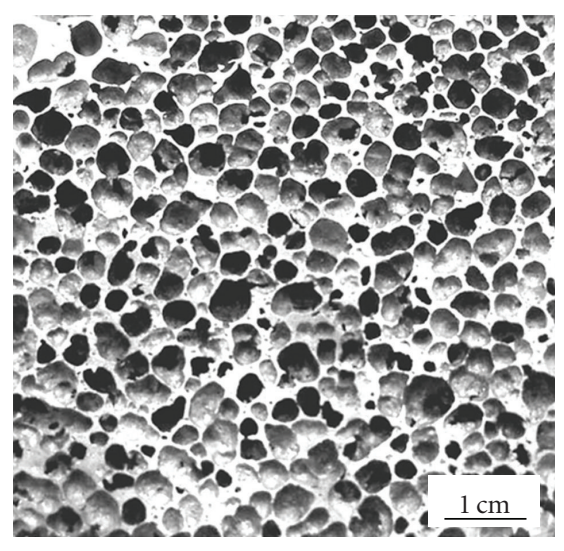

(a)

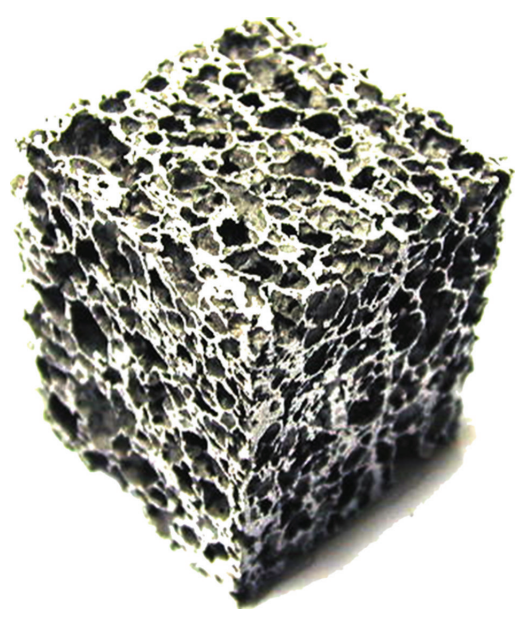

(b)

FIgURE 5: Digital optical image of (a) the cell morphology, and (b) isometric view (structure) of a typical Al-Si-Cu-Mg alloy foam. 


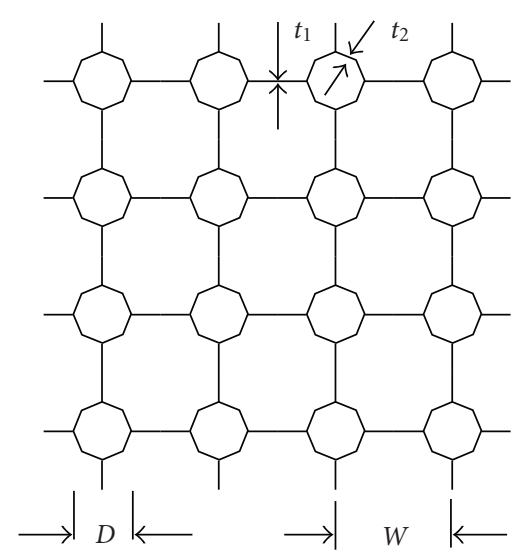

(a)

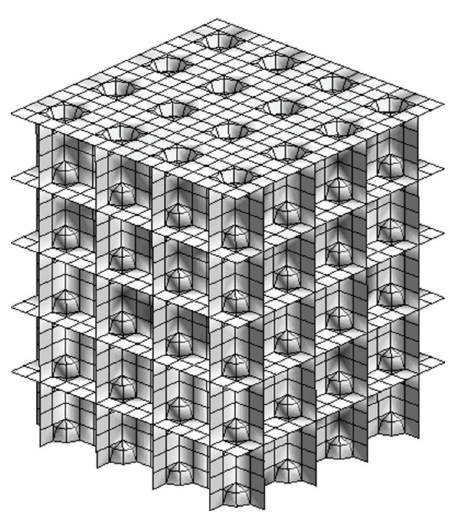

(b)

FIgURE 6: (a) Schematic diagram of the weaker cruciform-stronger-hemisphere model (a) top view (cell morphology), and (b) isometric view of a complete model.
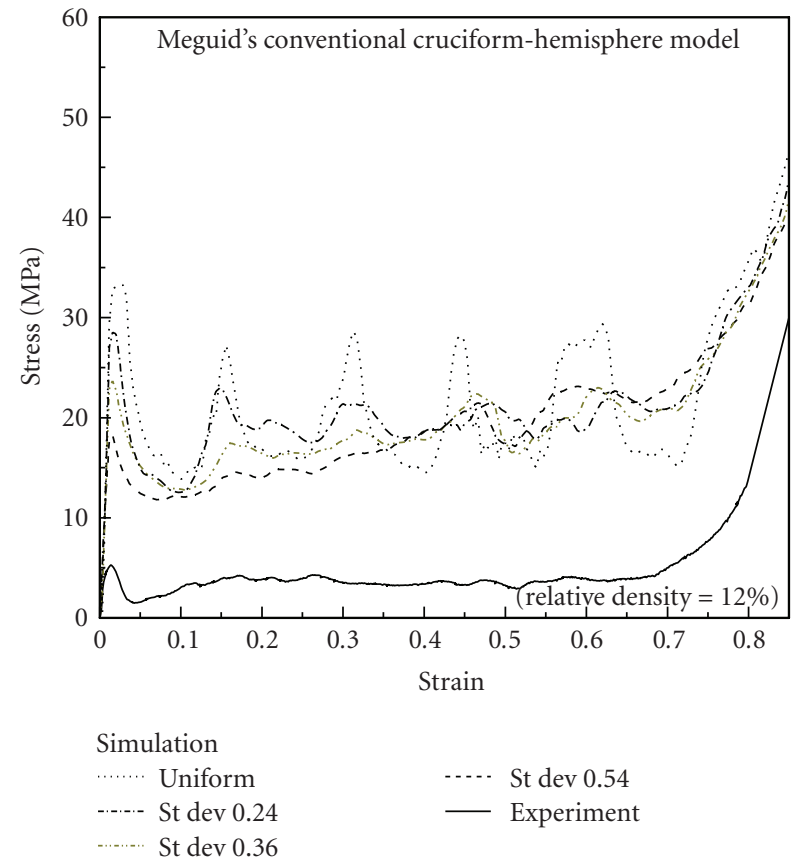

FIGURE 7: Experimental and simulated stress-strain curves using cruciform-hemisphere model, for a $12 \%$ relative density foam.

3.4. Meguid's Cruciform-Hemisphere Model. Meguid's cruciform-hemisphere model [23], as shown in Figure 4, is an improvement of Santosa's model, which replaced the pyramidal section of Santosa's truncated cube model with a hemispherical section. The relative density of this model is given by.

$$
\frac{\rho_{\text {foam }}}{\rho_{\text {solid }}}=3\left(\frac{t}{W}\right)+\frac{\pi}{4}\left(\frac{t}{W}\right)\left(\frac{D}{W}\right)^{2}
$$

where $D$ is the diameter of the hemispherical section, $t$ is the cell wall thickness and $W$ is the width of a unit cell.

For foams of known relative density and known cell wall material properties, the global mechanical properties that
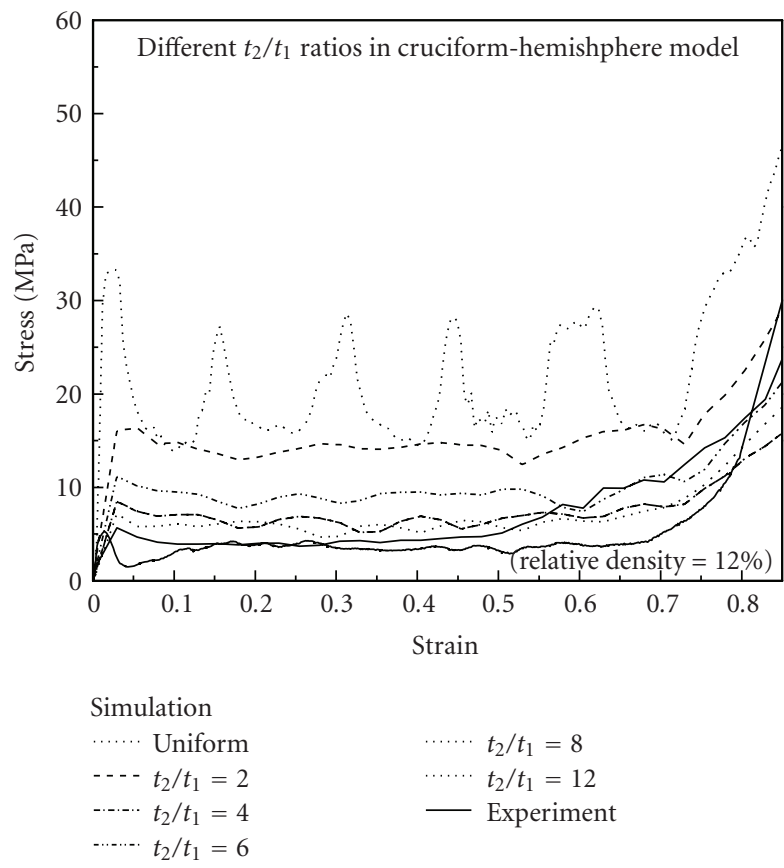

FIGURE 8: Variation of the stress-strain curve with change in thickness ratio in the cruciform-hemisphere model.

is, the elastic modulus and the plastic plateau stress for the skeleton cubic cell model, the tetracaidekehedral model, and the truncated cube model are calculated simply by using (4), (5), (7), (8), and (9), respectively. In cruciform-hemisphere model the mechanical properties are derived using finite element simulation. The numerical model is build up of shell elements. The input parameters for the model are $D, W, t$, $\rho_{\text {foam }}$ and $\rho_{\text {solid }}$, as well as the material properties of the cell wall. The relative density of the foam is generally known. For convenience, the ratio $D / W$ is kept fixed (for example Meguid et al. used $W=2 D$ ), and the value of $t$ is obtained from (12). For a model with $D=4 \mathrm{~mm}$, and $W=8 \mathrm{~mm}$ the value of $t$ for foams of relative density $12 \%$ and $20 \%$ becomes 


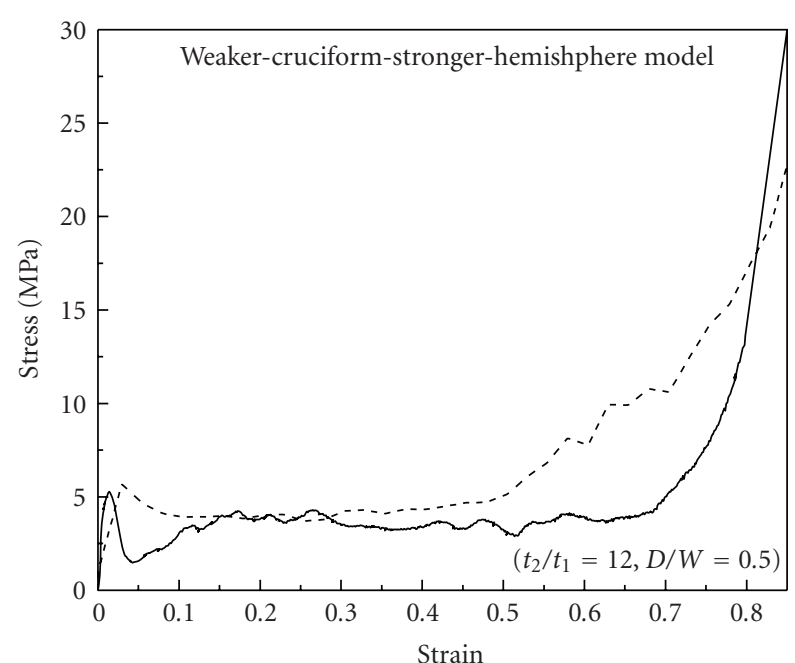

Relative density: $12 \%$

-..- Simulation

- Experiment

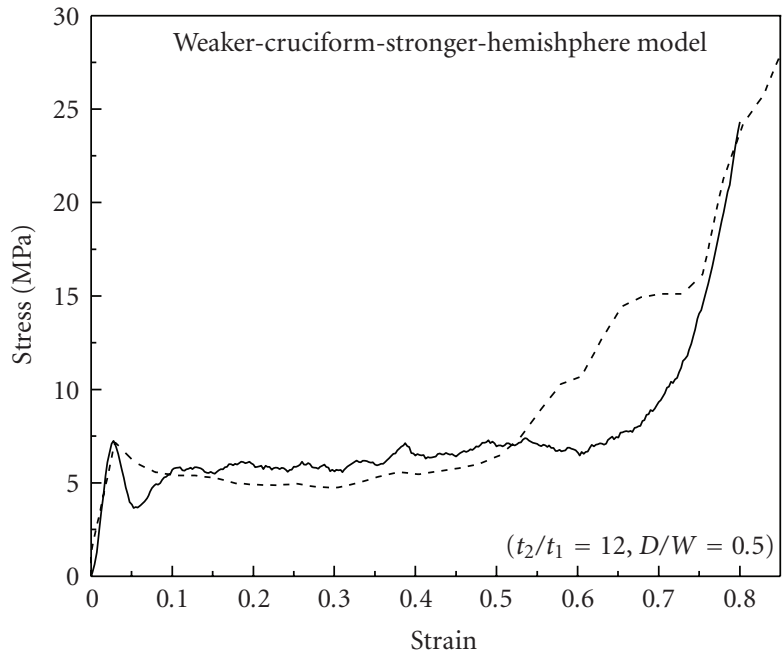

Relative density: $15 \%$

-..- Simulation

— Experiment

(a)

(b)

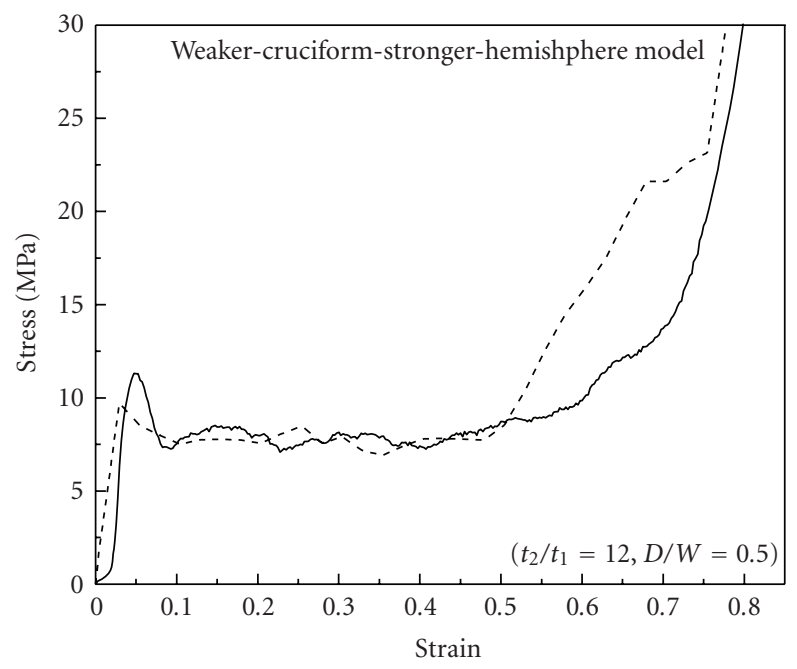

Relative density: $20 \%$

-..- Simulation

- Experiment

(c)

FIGURE 9: Experimental and simulated stress-strain curves using the improved weaker-cruciform-stronger-hemisphere model (a) relative density $=12 \%$, (b) relative density $=15 \%$, (c) relative density $=20 \%$.

$0.3003 \mathrm{~mm}$ and $0.5006 \mathrm{~mm}$ respectively. A numerical solver is then employed to obtain the load-displacement data which eventually gives the stress-strain curves and hence the elastic modulus, plastic plateau stress, and so fiorth. Section 4 presents the results obtained using the models described above along with the experimental results.

3.5. Simulation of Foam in the Current Study. In the current work, a multiple cell model was developed using the nonlinear explicit finite element code LS-DYNA. The model consisted of a total of 80 unit cells. The walls of the unit cells were represented by Belytschko Tsay shell elements. The material used was a user-defined material with the properties described in Section 2.2. The model used in this study are similar to those used by Meguid et al. [23], and Santosa and Wierzbicki [18]. Both of these works have been heavily cited in the literature of metal foams. The meshes used in the current work were replicas of the meshes used by Meguid et al. [23]. Therefore a mesh-sensitivity analysis was deemed unnecessary and was not performed.

The mean through-thickness density variation of the actual foam was measured by cutting a foam specimen into 

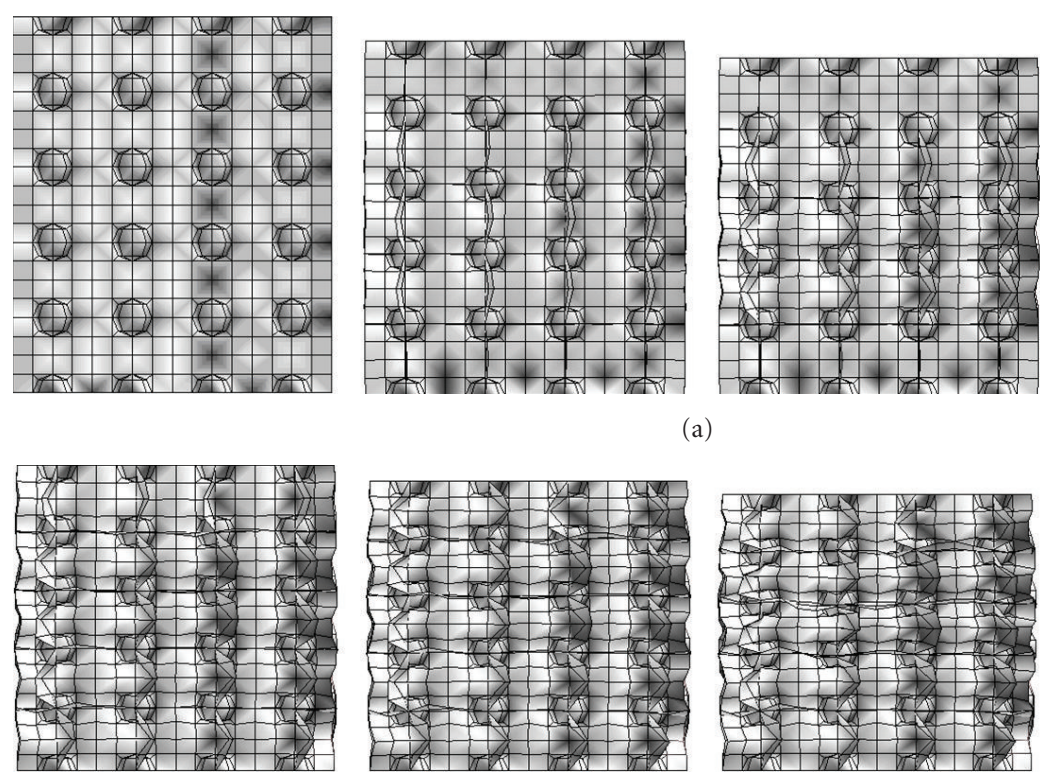

(a)
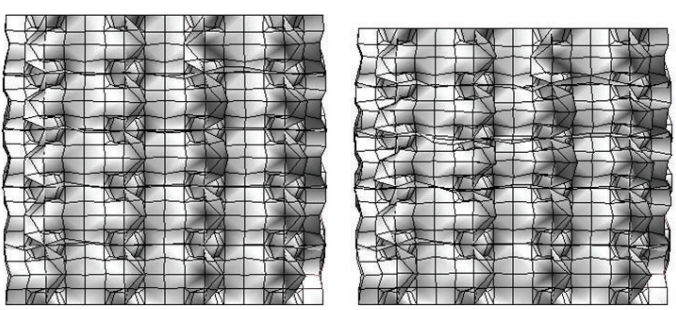

(b)
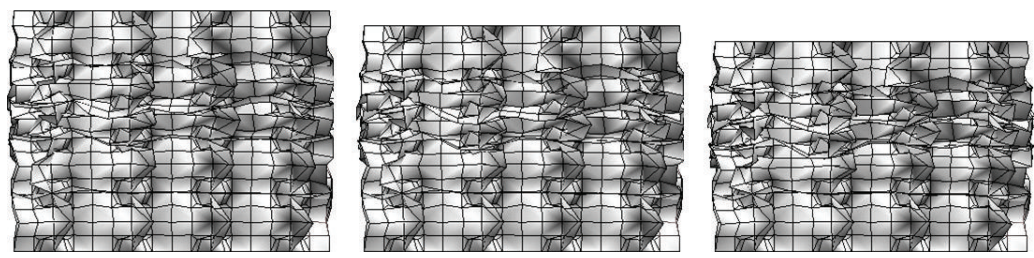

(c)
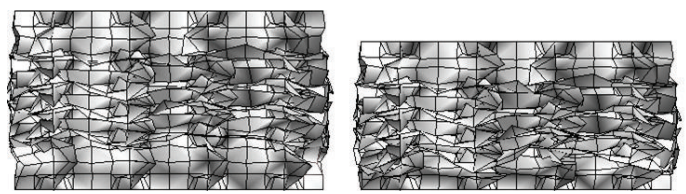
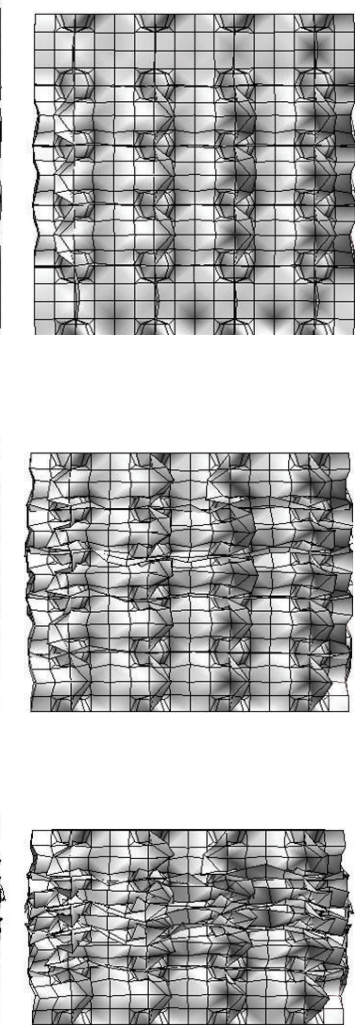

(d)

Figure 10: Two-dimensional views of the model in case of the deformation pattern-I: (simultaneous uniform deformation in all part of the foams) obtained from simulation using a uniform foam density.

TABle 1: Mechanical properties of a $12 \%$ relative density foam obtained from experiment and computation using existing foam models.

\begin{tabular}{lcc}
\hline Model & $\begin{array}{c}\text { Elastic modulus } \\
(\mathrm{GPa})\end{array}$ & $\begin{array}{c}\text { Plateau } \\
\text { stress/crushing } \\
\text { strength (MPa) }\end{array}$ \\
\hline Skeleton cube & 2.76 & 10.32 \\
Tetracaidekehedral & 3.05 & 13.44 \\
Truncated cube (Analytical) & N/A & 12.02 \\
Truncated cube (Simulation) & N/A & 20.00 \\
Cruciform-hemisphere & N/A & 15.00 \\
Experiment & 1.35 & 4.00 \\
\hline
\end{tabular}

five horizontal slices and evaluating the density of each layer separately. This through-thickness density variation was then implemented into the numerical model by assigning the five different measured densities to the five individual layers. The in-plane density variations were assumed to follow a statistical distribution with a standard deviation of $0.2,0.3$, and 0.4 times the mean value which means that for a foam of $12 \%$ mean relative density, the local relative density was varied over the range of $9 \sim 15 \%, 6 \sim 18 \%$, and $3 \sim 21 \%$, respectively. This density variation represents both the local variation in the foam density and internal defects such as inhomogeneous distribution of pores, second phase particle, inclusions [23].

\section{Results and Discussion}

The cell wall material properties of the foams obtained from nanoindentation were: Young's modulus, $E=79 \mathrm{GPa}$, with Poission's ratio, $v=0.33$. The Yield stress was $202 \mathrm{MPa}$. The true stress-strain data derived from simulation was converted to equivalent stress-strain data to be used in modeling with LSDYNA. 

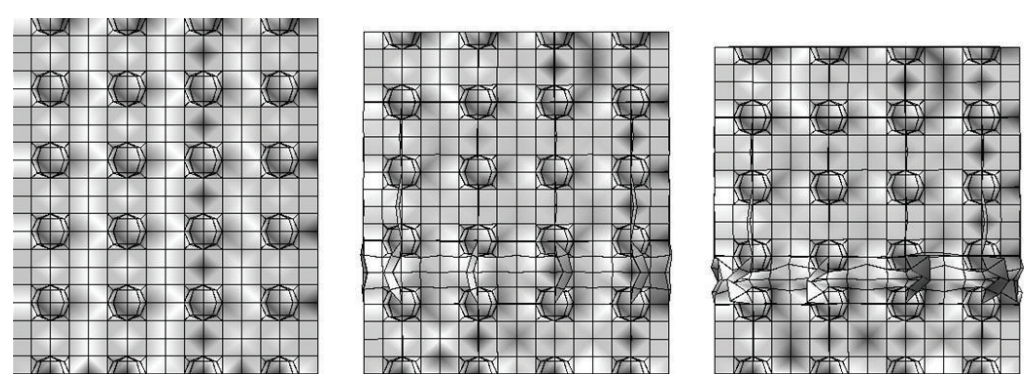

(a)
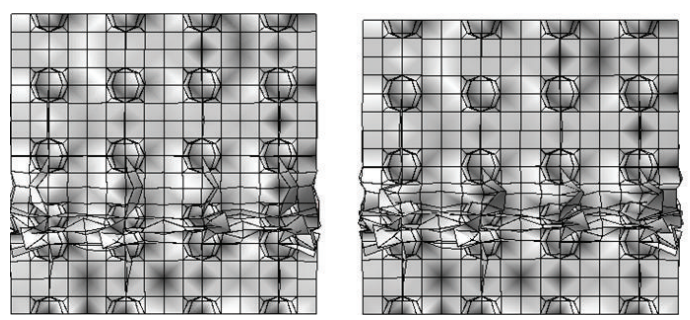

(b)
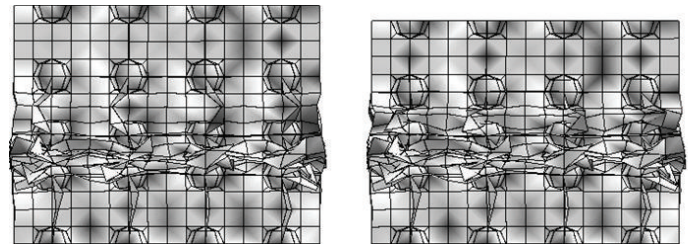

(c)
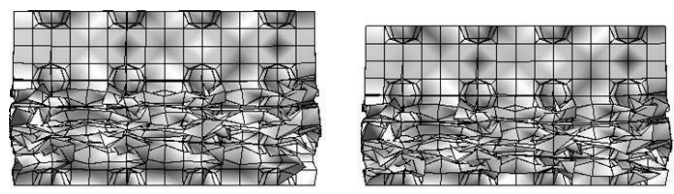
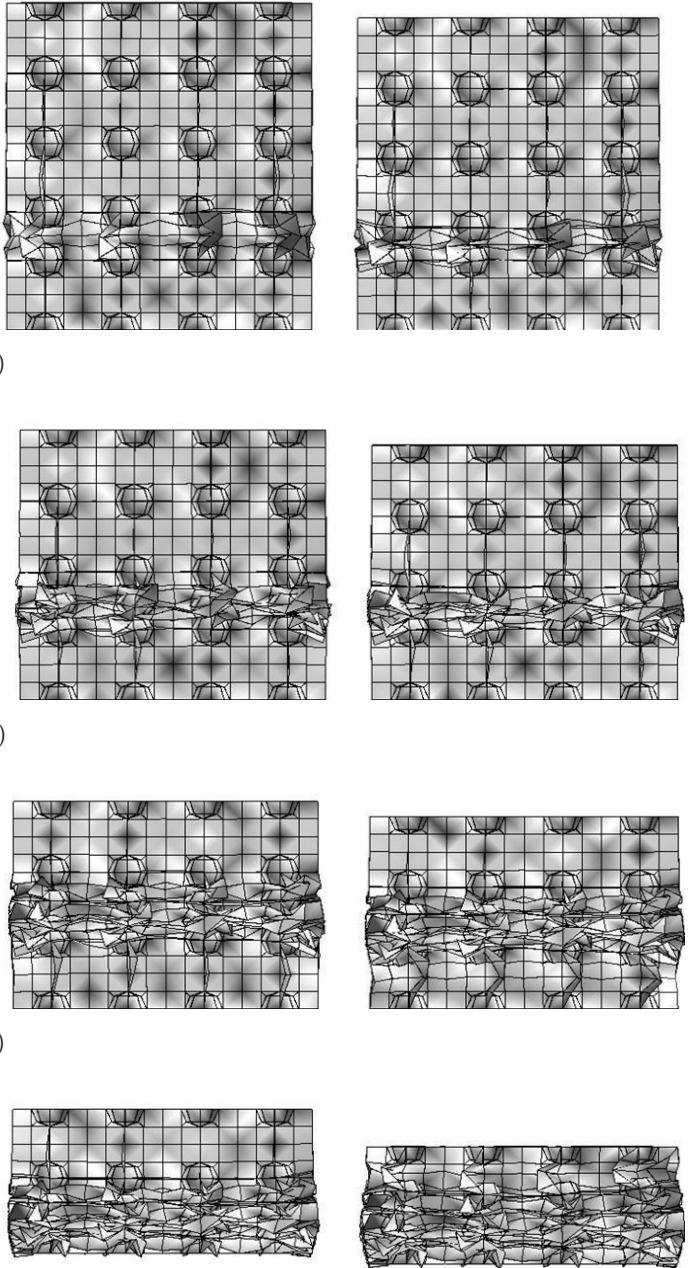

(d)

FIGURE 11: Two-dimensional views of the model in case of deformation pattern-II: (Layerwise deformation) obtained from simulation when the Layerwise thickness variation of foam was implemented in the model.

The elastic modulus and plastic plateau stress/crushing strength were computed for the foam of $12 \%$ relative density from the material stress-strain data for the models described above. The obtained values along with the experimental results are shown in Table 1. It is clear from Table 1, while the experimental elastic modulus and plastic plateau stress values for the $12 \%$ relative density foam were $1.35 \mathrm{GPa}$ and $4 \mathrm{MPa}$, respectively, those obtained from simulation using various models were in the range 2.75 to $3.05 \mathrm{GPa}$ and 10 to $20 \mathrm{MPa}$ respectively. It is thus evident from Table 1 that the existing models of the foam over predict the mechanical properties of foams. For better prediction of foam behaviors it is therefore necessary to have a better foam model. In the following section an improved model of foam has been proposed for simulation of closed-cell Al-alloy foams.

4.1. An Improved Foam Model. Figures 5(a) and 5(b) show the digital optical image of the cell morphology and the structure of a typical Al-alloy foam [21]. A careful observation of these images reveals that the distribution of solid throughout the cells is not uniform. Much of the solid seems to be accumulated near the junctions of cells compared to that in the cell walls. This indicates that the junction areas of larger cells (where the smaller cells are located) are stronger than the cell wall areas of larger cells. Moreover the cell walls of the smaller cells seem to be thicker than those of the larger cells. Based on this observation, an improved model for closed-cell Al-alloy foam is developed, introducing a new parameter in the Meguid's cruciform-hemisphere model. The introduced parameter is the thickness ratio between the smaller and larger cells, that is, the thickness ratio between the hemispherical and cruciform sections of the model unit cell. The cell morphology and the structure of the simulation model using the improved weaker-cruciformstronger-hemisphere model are shown in Figures 6(a) and 6(b). The relative density for this improved model is given 

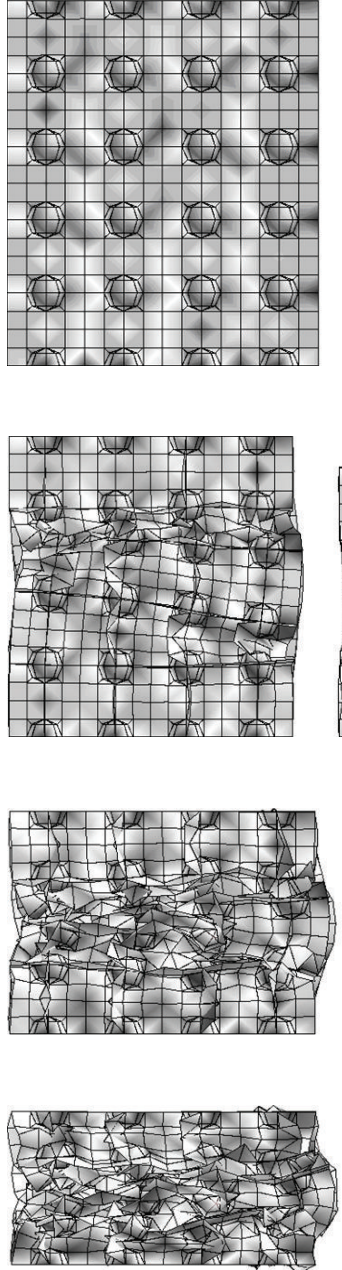
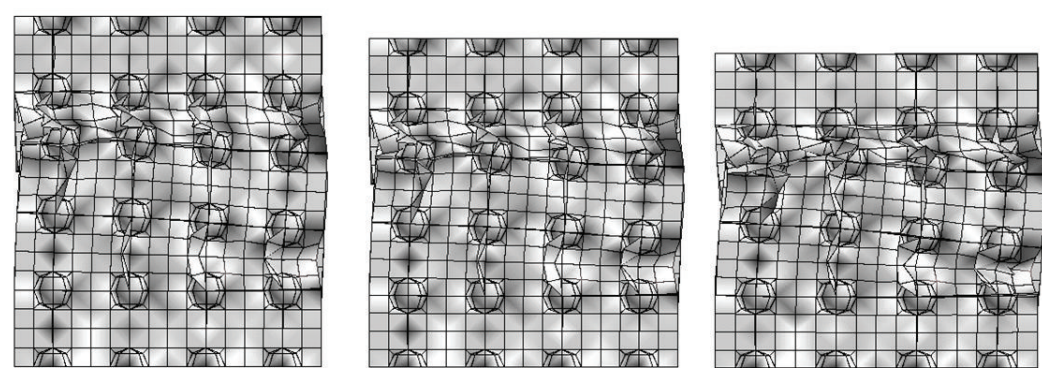

(a)
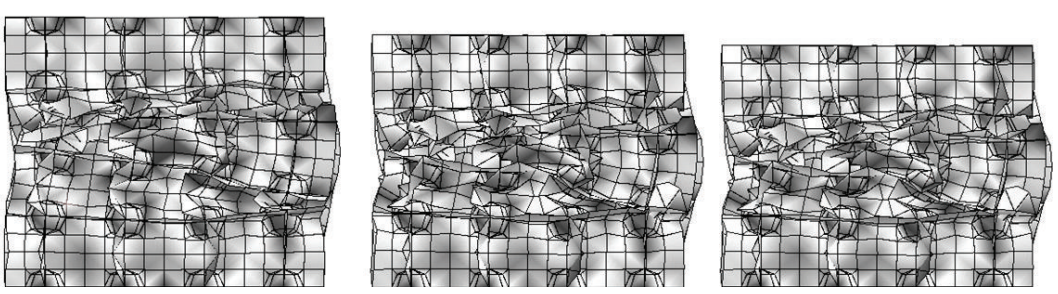

(b)
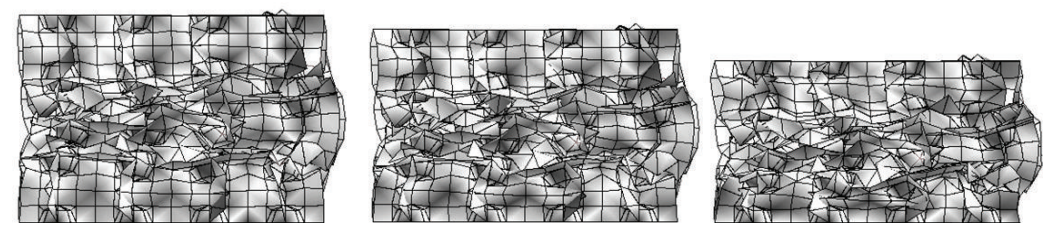

(c)
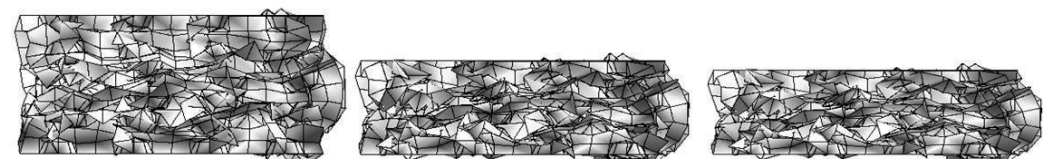

(d)

Figure 12: Two-dimensional views of the model in case of deformation pattern-III: (Irregular deformation ) obtained from simulation when both the in-plane and through thickness density variations were implemented.

[21] by

$$
\begin{aligned}
\frac{\rho_{\text {foam }}}{\rho_{\text {solid }}}= & 3\left[1-\frac{\pi}{4}\left(\frac{D}{W}\right)^{2}\right]\left(\frac{t_{1}}{W}\right) \\
& +\frac{1}{6} \pi\left[6\left(\frac{D}{W}\right)^{2}+12\left(\frac{D}{W}\right)\left(\frac{t_{2}}{W}\right)+8\left(\frac{t_{2}}{W}\right)^{2}\right]\left(\frac{t_{2}}{W}\right),
\end{aligned}
$$

where, $D$ and $W$ are the same as in (12), while $t_{1}$ and $t_{2}$ are the wall thickness of the cruciform and the hemispherical sections, respectively. Values of $D$ and $W$ are known from the geometry of the model unit cell, for example $D=4 \mathrm{~mm}$ and $W=8 \mathrm{~mm}$ in Figure 6 . Taking arbitrary values for the ratio $t_{2} / t_{1},(13)$ can be solved to obtain $t_{1}$ and $t_{2}$.

The cruciform-hemisphere model is believed to follow the experimental results more closely [23] when the local density variation of foam is implemented in the model. In this study, the local density is therefore varied in numerical model using a wide range of standard deviation as mentioned in Section 3.5. In the model, the value used for the thickness ratio $\left(t_{2} / t_{1}\right)$ was varied, the value always being greater than 1.0 , indicating that the wall thickness of the hemispherical sections (which represents the smaller cells of the foams) are higher than those of the cruciform sections. Simulation of the uniaxial compression test was performed using nonlinear explicit finite element code LS-DYNA for the model shown in Figure 6(b), and foams of relative density $12 \%-20 \%$.

The stress-strain curves for a $12 \%$ relative density foam obtained from the conventional cruciform-hemisphere model by implementing local density variation with different standard deviations, as proposed by Meguid et al. [23], are shown in Figure 7. It is quite clear that the plateau stresses obtained from the conventional model are much higher compared to the experimental result. The stress in the lower strain range decreases slightly as the degree of inhomogeneity is increased (i.e., the standard deviation value is raised from 0.24 to 0.54 ); however, the decrease of the plateau stress is very small, and the predicted results are still very high compared to the experimental curve. The results obtained 

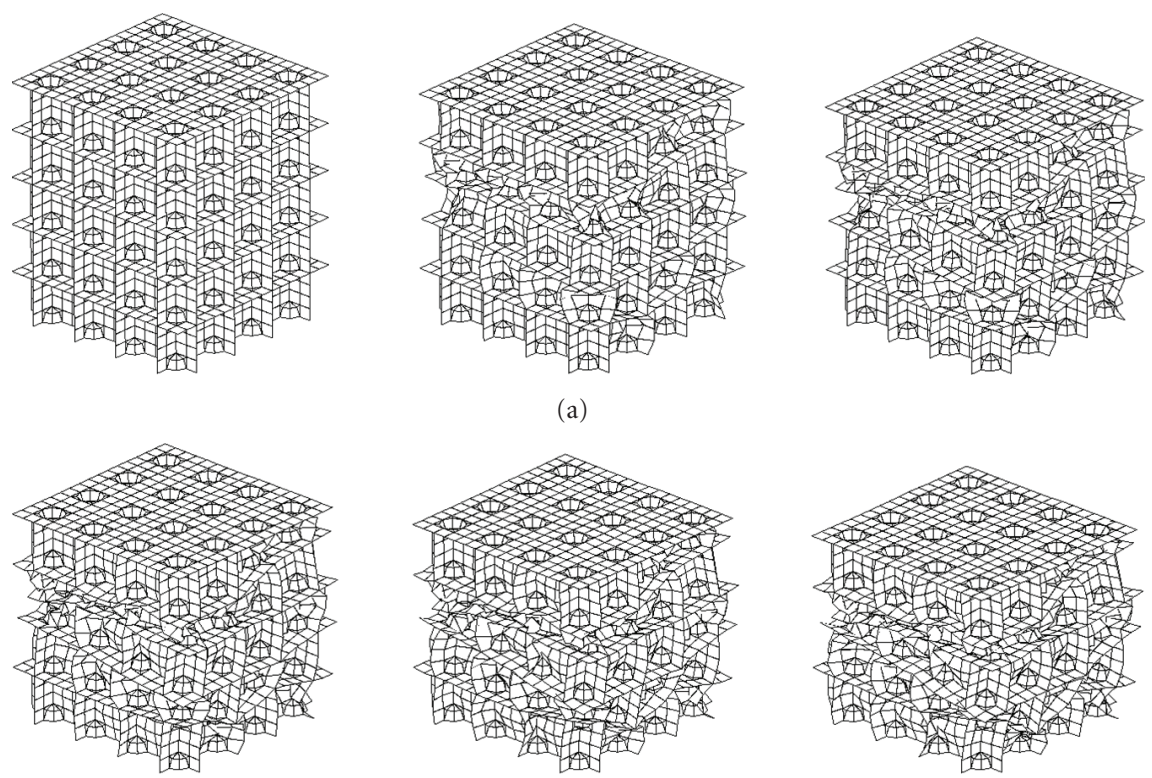

(a)
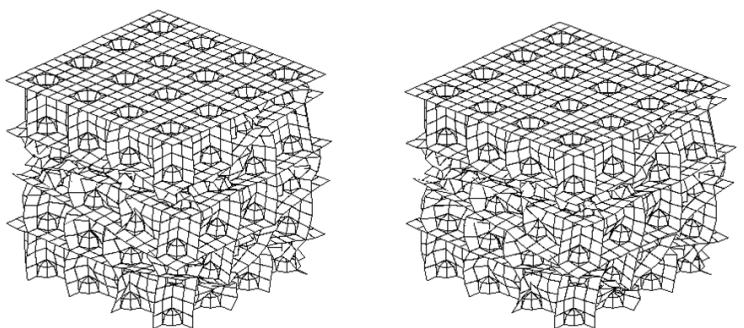

(b)
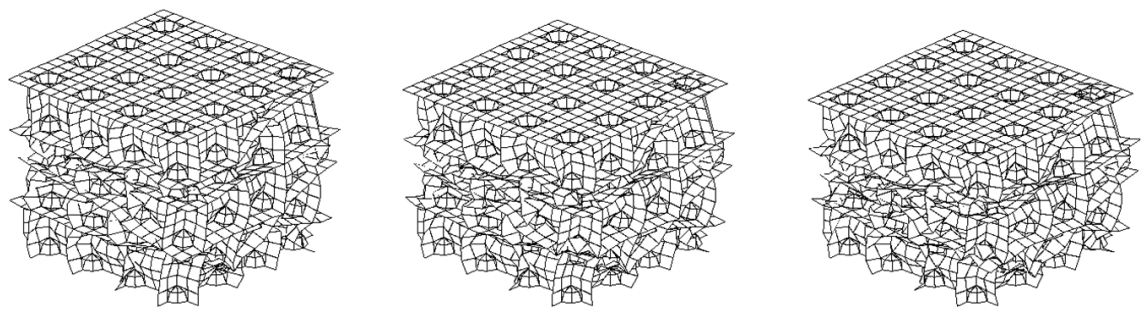

(c)
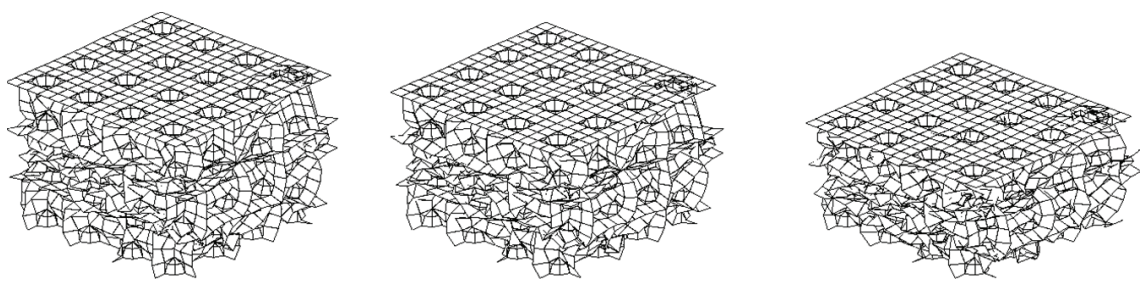

(d)

FIGURE 13: Isometric views of deformation pattern-III: deformation through irregular band formation, obtained from simulation when both the in-plane and through thickness density variations were implemented (same as the case presented in Figure 12).

from simulation for different thickness ratios of, the cell walls in our proposed improved model are shown in Figure 8. The plateau stress in Figure 8 decreases as the thickness ratio is increased. The plateau stress region of numerically obtained curves showed best agreement with the experimental curve when the thickness ratio, $t_{2} / t_{1}$ was 12 . Figures $9(\mathrm{a})$, 9(b), and 9(c) present the experimental and the simulation results for $12 \%, 15 \%$, and $20 \%$ relative density foams using the weaker cruciform-stronger-hemisphere model with a thickness ratio, $t_{2} / t_{1}=12$. It is evident from Figure 9 that the new model with a thickness ratio, $t_{2} / t_{1}=12$ predicts the foam plateau stress very well for all three foams used in this study. The ratio $t_{2} / t_{1}=12$ apparently seems to be very high. However, given the fact that the smaller cells (with thickness $t_{2}$ ) represent the junction areas of larger cells (thickness $t_{1}$ ) where much of the solid seems to accumulate, the value is not unrealistic. It should be noted that the foams used in this study were Al-3wt.\%Si-2wt.\%Cu-2wt.\%Mg alloy foams. For foams of other compositions, the cell morphology may be different, and thus different values of thickness ratio may be required.

4.2. Deformation Pattern of the Improved Foam Model. It was found that the new weaker-cruciform-stronger-hemisphere model is capable of producing all three different types of deformation pattern of closed-cell metal foams. The deformation patterns of the weaker-cruciform-strongerhemisphere model resulted from simulation, for uniform thickness, Layerwise density variation and random density variation are shown in Figures 10, 11, and 12, respectively. 
It is clear form Figure 10 that the new model shows a simultaneous uniform deformation in all part of the foam if a uniform thickness is assigned to the model. When the Layerwise density variation, which occurs in $\mathrm{Al}$-alloy foams because of drainage of liquid due to gravitational attraction and low viscosity of fluid, is implemented in the model, it produces Layerwise deformation bands, as shown in Figure 11, where the deformation starts in a particular layer and is propagated to subsequent layers only after the first deformation band is completely collapsed. The third deformation pattern is realized when both the in-plane and through thickness density variations of foam are implemented in the model. In this third type of deformation pattern, the deformation initiated in the locations of lowest densities and highest impurities, being independent from each other. As the deformation continues, the initially deformed regions become linked with each other and form deformation bands, as shown in Figure 12, which continue to grow until the foam completely collapses. Figure 13 shows the isometric views of the timesequence of deformation pattern for the case presented in Figure 12. The deformation patterns, in the current study, for the stress-strain graphs presented in Figures 5 to 7 were similar to those shown in Figures 12 and 13. The pattern of deformation in the compressive test experiment was also similar to this third type of deformation pattern.

\section{Conclusions}

Cell wall material properties of Al-alloy foams have been obtained using nanoindentation test and FE simulation. Constitutive behaviors of various existing FE models of closed-cell Al-alloy foams have been discussed. The accuracy of the models in predicting compressive mechanical properties of foams has been verified. A new model named as weaker-cruciform-stronger-hemisphere model has been proposed and developed. The new model predicts the mechanical properties of foams with much better accuracy compared to the existing conventional models. The newly developed model is found to be capable of producing all three different types of deformation pattern of closed-cell metal foams, namely, simultaneous uniform deformation, Layerwise deformation, and the progressive deformation from the locations of lowest densities and highest impurities to those of higer densities and lower impurities.

\section{Acknowledgments}

The author gratefully acknowledges the helpful advice from late Professor Amkee Kim, and Professor Seong Sik Cheon of Kongju National University, South Korea, Dr. Hak Joo Lee of Korea Institute of Machinery and Materials, South Korea, and Professor Carlos F. Lange of University of Alberta, Canada. The Al-alloy foams used in this study was obtained from Professor Seong Seock Cho of Chungnum National University, South Korea.

\section{References}

[1] A. Kim, M. A. Hasan, S. H. Nahm, and S. S. Cho, "Evaluation of compressive mechanical properties of Al-foams using electrical conductivity," Composite Structures, vol. 71, no. 2, pp. 191-198, 2005.

[2] A. Kim, S.-S. Cheon, M. A. Hasan, and S.-S. Cho, "Bending behavior of thin-walled cylindrical tube filled with aluminum alloy foam," Key Engineering Materials, vol. 270-273, no. I, pp. 46-51, 2004.

[3] F. Baumgärtner, I. Duarte, and J. Banhart, "Industrialization of powder compact foaming process," Advanced Engineering Materials, vol. 2, no. 4, pp. 168-174, 2000.

[4] I. Duarte and J. Banhart, "A study of aluminium foam formation-kinetics and microstructure," Acta Materialia, vol. 48, no. 9, pp. 2349-2362, 2000.

[5] A. Kim, M. A. Hasan, H. J. Lee, and S. S. Cho, "Characterization of submicron mechanical properties of Al-alloy foam using nanoindentation technique," Materials Science Forum, vol. 475-479, pp. 4199-4202, 2005.

[6] A. Kim, K. Tunvir, S. S. Cheon, G. D. Jeong, S. H. Lee, and M. A. Hasan, "Effect of structural inhomogeneity of Alalloy foams on the deformation behavior and plastic plateau stress by cruciform-hemisphere FE modeling," in Proceedings of International Conference on Recent Advances in Mechanical and Materials Engineering (ICRAMME '05), Kualalumpur, Malayasia, May 2005, paper \#131.

[7] M. A. Hasan and A. Kim, "Effect of foaming time and temperature on the hardness of Al-Si-Cu-Mg alloy foam cell walls," International Review of Mechanical Engineering, vol. 3, no. 1, pp. 39-47, 2009.

[8] M. A. Hasan, A. Kim, and H.-J. Lee, "Measuring the cell wall mechanical properties of Al-alloy foams using the nanoindentation method," Composite Structures, vol. 83, no. 2, pp. 180-188, 2008.

[9] R. Edwin Raj, V. Parameswaran, and B. S. S. Daniel, "Comparison of quasi-static and dynamic compression behavior of closed-cell aluminum foam," Materials Science and Engineering A, vol. 526, no. 1-2, pp. 11-15, 2009.

[10] F. G. Cuevas, J. M. Montes, J. Cintas, and P. Urban, "Electrical conductivity and porosity relationship in metal foams," Journal of Porous Materials, vol. 16, no. 6, pp. 675-681, 2008.

[11] C. Torres-Sánchez and J. Corney, "Identification of formation stages in a polymeric foam customised by sonication via electrical resistivity measurements," Journal of Polymer Research, vol. 16, no. 5, pp. 461-470, 2009.

[12] I. Sevostianov and M. Kachanov, "Connections between elastic and conductive properties of heterogeneous materials," Advances in Applied Mechanics, vol. 42, pp. 69-252, 2009.

[13] A. Kim, A. Hasan, S. S. Choen, and H. J. Lee, "The constitutive behavior of metallic foams using nanoindentation technique and FE modeling," Key Engineering Materials, vol. 297-300, pp. 1050-1055, 2005.

[14] A. G. Hanssen, L. Lorenzi, K. K. Berger, O. S. Hopperstad, and M. Langseth, "A demonstrator bumper system based on aluminium foam filled crash boxes," International Journal of Crashworthiness, vol. 5, no. 4, pp. 381-392, 2000.

[15] H. J. Chung, K. Y. Rhee, B. S. Han, and Y. M. Ryu, "Plasma treatment using nitrogen gas to improve bonding strength of adhesively bonded aluminum foam/aluminum composite," Journal of Alloys and Compounds, vol. 459, no. 1-2, pp. 196202, 2008. 
[16] H.-B. Wang, S.-H. Liang, P. Xiao, and Z.-K. Fan, "Influence of rare earths on microstructure and damping capacity of ZA alloy foam," Chinese Journal of Nonferrous Metals, vol. 17, no. 10, pp. 1685-1689, 2007.

[17] R. Rajendran, K. Prem Sai, B. Chandrasekar, A. Gokhale, and S. Basu, "Preliminary investigation of aluminium foam as an energy absorber for nuclear transportation cask," Materials and Design, vol. 29, no. 9, pp. 1732-1739, 2008.

[18] S. Santosa and T. Wierzbicki, "On the modeling of crush behavior of a closed-cell aluminum foam structure," Journal of the Mechanics and Physics of Solids, vol. 46, no. 4, pp. 645669, 1998.

[19] A. G. Hanssen, O. S. Hopperstad, M. Langseth, and H. Ilstad, "Validation of constitutive models applicable to aluminium foams," International Journal of Mechanical Sciences, vol. 44, no. 2, pp. 359-406, 2002.

[20] L. J. Gibson and M. F. Ashby, Cellular Solids, Cambridge University Press, Cambridge, UK, 2nd edition, 1997.

[21] M. A. Hasan, The constitutive behaviour of metallic foams using nanoindentation technique and FE modelling, M.S. thesis, Kongju National University, Kongju, South Korea, 2005.

[22] A. E. Simone and L. J. Gibson, "Aluminum foams produced by liquid-state processes," Acta Materialia, vol. 46, no. 9, pp. 3109-3123, 1998.

[23] S. A. Meguid, S. S. Cheon, and N. El-Abbasi, "FE modelling of deformation localization in metallic foams," Finite Elements in Analysis and Design, vol. 38, no. 7, pp. 631-643, 2002. 

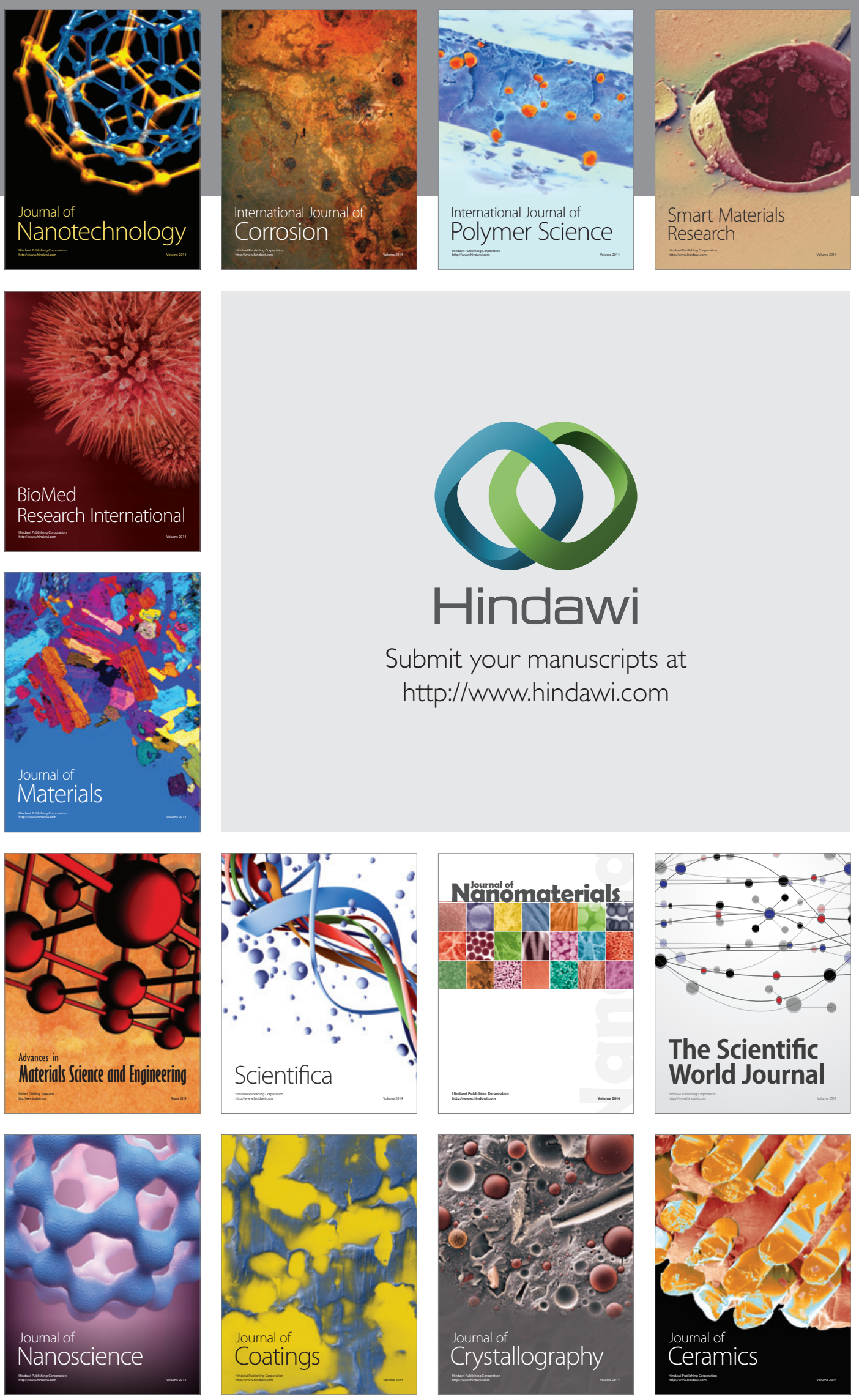

The Scientific World Journal

Submit your manuscripts at

http://www.hindawi.com

\section{World Journal}

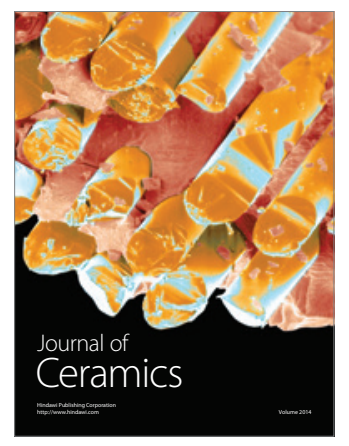

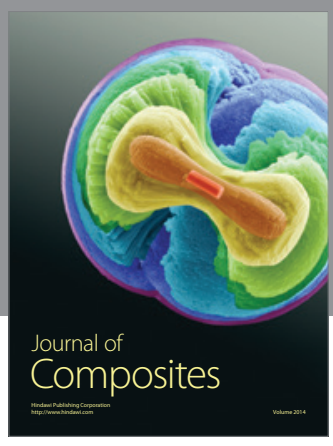
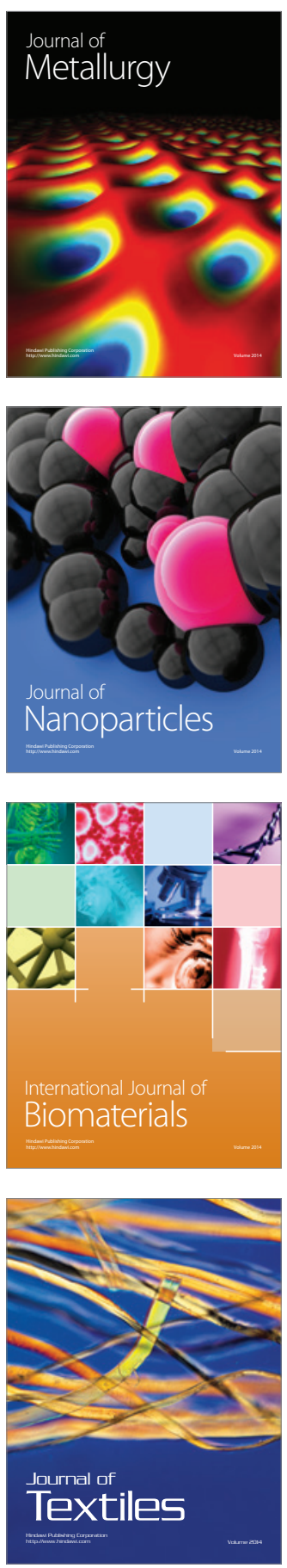